\title{
Method for Innovative Cultivation of Amateur Basketball Reserve Talents in Colleges and Universities
}

\author{
Yunpeng $\mathrm{Zhao}^{1}$ Suwen $\mathrm{Li}^{1, *}$ Bingbo $\mathrm{He}^{1}$
}

${ }^{1}$ Kunming University, Kunming, Yunnan 650214, China

${ }^{*}$ Corresponding author.

\begin{abstract}
Collaborative innovation based cultivation of amateur basketball reserve talents in colleges and universities is very important and is a way to provide professional basketball talents to the national basketball team. However, there are still many problems in this work. It is difficult to truly realize collaboration and innovation in cultivation of such talents. This article briefly discusses the current situation and significance of the cultivation of amateur basketball reserve talents in colleges and universities, and discusses the specific implementation methods and measures, and makes an in-depth discussion on the detailed implementation method and measure in combination with the problems in collaborative innovation based cultivation of such talents, in order to reach a good talents cultivation effect.
\end{abstract}

Keywords: amateur basketball, reserve talents, collaborative innovation, cultivation measures

\section{INTRODUCTION}

According to the characteristics of college sports work, strengthening the cultivation of amateur basketball reserve talents will help improve the overall level of basketball and sports in colleges and universities. This is very beneficial to the development of college basketball undertaking in China and the selection of athletic talents in this field. In the multieducational environment, colleges and universities should pay enough attention to this work, reform the past basketball teaching content, ideas, methods and so on, make collaborative innovation in cultivating highquality reserve talents, and call on the talents to actively participate in amateur basketball training.

\section{STATUS OF CULTIVATION OF AMATEUR BASKETBALL RESERVE TALENTS IN COLLEGES AND UNIVERSITIES}

Chinese universities have resource advantages in the process of physical education. However in the field of sports, the talent cultivation model is too old and is in a period of transformation and development. This just illustrates the importance of cultivating basketball talents in colleges and universities. In this context, the national basketball talents cultivation model is too traditional, and has many problems and disadvantages; a reform is needed urgently. On the other hand, colleges and universities still have outstanding advantages in the cultivation of athletic talents, as they can provide a broad platform for the cultivation of national basketball reserve talents, enabling this work to proceed smoothly.
In practice, the cultivation of basketball talents in China needs to undergo the transition from teenager teams to youth teams and then to professional teams. However, the emergence of Chinese University Basketball Association (CUBA) has broken the system. This event promotes the overall development and comprehensive level of college basketball in China, and makes college basketball games more fair and just. However in aspect of athletes' qualifications, CUBA has very strict requirements and a high positioning, so that some college reserve basketball talents ineligible to participate in the event [1]. Moreover, CUBA is too simplex in form; it is difficult to realize comprehensive cultivation of reserve basketball talents in primary school, middle school and university, so that this work is not systematic enough and many colleges and universities are incompetent to cultivate amateur basketball reserve talents.

Based on the above considerations, colleges and universities should recognize the importance of amateur basketball reserve talents cultivation, ensure that this work is consistent with CUBA's requirements, and reform on the basis of the previous basketball talent cultivation system to enable college amateur basketball reserve talents cultivation system possesses multiple characteristics in terms of form, level, and channel. Among them, the most critical content is to make coordinative innovation on China's sports system in accordance with the specific conditions of universities and colleges, and truly achieve the goal of Collaborative innovation based cultivation of amateur basketball reserve talents in colleges and universities. 


\section{THE SIGNIFICANCE OF COLLABORATIVE INNOVATION BASED CULTIVATION OF SUCH TALENTS}

\section{A. Comprehensive cultivation of such talents}

In the context of education system reform and pluralistic society, the concept of cultivating amateur basketball reserve talents in colleges and universities is different from that in the past. In addition to meeting social needs, the cultivation should also be comprehensive. The talents cultivated also need to have strong professional skills in the field of basketball. This education model is special, and is only arranged systematically and implemented comprehensively inside colleges and universities. In order to achieve the expected talent cultivation goals and make the talents adaptable to the college basketball cultivation content and intensity, collaborative innovation must be emphasized.

According to the requirements of collaborative innovation in cultivation of amateur basketball reserve talents in colleges and universities, the educational purpose should be determined so that the work has a rich cultural and psychological education support; and the nationwide sports system also makes the school education development environment more favorable and high-quality. Relying on model innovation, this work can become more professional, facilitate students' long-term and comprehensive development, and ensure that the basketball reserve talents are always in a good and comprehensive development state [2]. In addition, school should also make use of professional teachers to provide a professional cultivation environment for college amateur basketball reserve talents, so that they can possess strong basic basketball competences. School should coordinate with college physical education to test the professional state of the basketball reserve talents to diversify the model and content of amateur basketball reserve talents cultivation and improve the quality and efficiency of basketball teaching.

Applying the concept and method of "collaborative innovation" to the cultivation of amateur basketball reserve talents in colleges and universities can rely on innovation and reform to make college basketball talent cultivation content and methods more diverse, meet the national basketball reserve talents cultivation requirements and goals, always adhere to the peopleoriented principle, and meet the individual needs of reserve talents. All of those factors can lay a good foundation for the Collaborative innovation based cultivation of amateur basketball reserve talents in colleges and universities, and to a certain extent, ensure the scientific and orderly natures of the work [3].

\section{B. Improving the efficiency of basketball work in colleges and universities}

For a long time, amateur sports training is indispensable in physical education in colleges and universities. It should be regarded as a key college physical education work and concerned by relevant departments. Against this educational background, the collaborative innovation between sports system and college education perfects the cultivation of reserve basketball talents in colleges and universities, and enriches the undertaking of sports. Through the cultivation of reserve basketball talents, it is possible to realize in-depth development of college basketball sports, facilitate the implementation of moral education, patriotism education, and mental health education, ensure that the proportion of college physical education is increased to a certain extent, and provide a free and relaxed basketball training environment for college students.

In the process of amateur basketball reserve talents cultivation in colleges and universities, flexible application of collaborative innovation model will help building up college amateur sports athletic brand, stimulate college students' sports participation enthusiasm and positivity, focusing on their personal health, and helping them develop lifelong good exercise habits [4]. Based on the development status of China's basketball industry, it can be seen that collaborative innovation based education can broaden the channel for the delivery of athletic basketball talents, significantly improve the efficiency of sports work in colleges and universities, and further promote the overall development of China's overall basketball industry.

\section{MEASURES FOR THE COLLABORATIVE INNOVATION BASED CULTIVATION}

The collaborative innovation based cultivation of amateur basketball reserve talents in colleges and universities is a long-term task that cannot be achieved overnight. This puts forward relatively high requirements for college physical education and basketball teaching. In the course and training practice, it is not only needed to change the collaborative innovation based cultivation goal of college amateur basketball reserve talents, but also needed to pay attention to the reform of basketball competition system to achieve the expected talents cultivation goal and significantly improve the quality and efficiency of this work.

\section{A. Changing the cultivation goal}

In the collaborative innovation based cultivation of amateur basketball reserve talents in colleges and universities, specific educational goal must be determined to make the work more scientific and orderly. Affected by this model, the work of education 
on college basketball reserve talents should pay attention to the determination of goals. At the present stage, quality education is highly popular. Physical education should focus on the characteristics of college students and emphasize cultivating the comprehensive ability of college students and flexibly set the teaching goals on this basis. In the cultivation of amateur basketball reserve talents in colleges and universities, it is necessary to make clear that the purpose of this work is to promote the comprehensive and harmonious development of athletic basketball talents and promote their healthy physical and mental growth. At the same time, colleges and universities should also know about the overall characteristics and needs of amateur basketball reserve talents, so that the form and content of sports activities and competitive games are more diverse. In this context, school should take into overall consideration the college basketball reserve talents, ensure they can undergo comprehensively coordinated and sustainable development, promote the comprehensive improvement of college's comprehensive teaching levels, software and hardware facilities, and finally achieve the goal of cultivating college amateur basketball reserve talents and always ensure the smooth development and proceeding of this work [5].

\section{B. Reforming the competition system}

In order to meet the requirements of collaborative innovation, colleges and universities need to reform the previous competition model, and cultivate high-level student athletes in accordance with the connotation of sports culture and the requirements for talents cultivation, in the people-education oriented principle. The traditional college competition system places high requirements on the professional ability of amateur basketball reserve talents. It takes advantage of the "three-dimensional training" thinking mode and determines basketball competition mechanism, so that basketball players have only three segments of experience: teenager sports school, professional youth team, and professional adult team. In this context, basketball players place too much emphasis on skills training; their professional qualities and comprehensive competences are seriously inadequate. However, the cultivation of amateur basketball reserve talents in universities also faces the same dilemma. In this process, the cultural atmosphere in colleges and universities has been directly ignored, and relevant departments and personnel have not yet recognized their important role in the collaborative innovation based cultivation of amateur basketball reserve talents [6]. Based on the above considerations, in the context of this model, it is necessary to make "collaborative innovation" in the national sports system and school physical education, reform the basketball competition system. School should not only pay attention to the athletic sports and games of colleges and universities but also develop the intellectual potential of athletes on the basis of competition evaluation mechanism, and always pay attention to the comprehensive competences and psychological state of basketball players.

\section{NOTICES FOR THE COLLABORATIVE INNOVATION BASED CULTIVATION}

In the collaborative innovation based cultivation of amateur basketball reserve talents in colleges and universities, there are a lot of relevant contents to be noted. In this context, school should both focus on the construction of the management system, and improve the quality of basketball coaches and players, to ensure that the talent cultivation can be more scientific and standardized.

\section{A. Building a scientific and reasonable management system}

It is needed to unify the forms of sports and education, create a dual-responsibility (sports system and school) system, and call on leaders at all levels to participate in the management on the basis of the joint office system. Contracts, deeds and other documents can be entered to define the rights, interests, and responsibilities of college amateur basketball reserve talents in the match and formulate relevant rules and regulations. Based on the running status, colleges and universities can establish a competition system to reflect the value of collaborative innovation based cultivation of college amateur basketball reserve talents in the way of "survival of the fittest" [7]. In addition, it is necessary to adopt a hierarchical responsibility system to strengthen the internal management of colleges and universities and simplify the specific management processes and methods. The management agency should also establish various systems such as dispute arbitration, academic qualifications, and participation qualifications. In the implementation of the systems, the agency must maintain fair, open, and justice, to facilitate the cultivation of college basketball reserve talents, and improve the quality of Chinese athletic sports.

\section{B. Improving the quality of basketball coaches}

Based on the collaborative innovation based cultivation goals and requirements of amateur basketball reserve talents in colleges and universities, the training on college physical education teachers and basketball coaches should be put in place, so that it is not limited to school education, but fundamentally has a comprehensive control of the global basketball development direction, advanced basketball training methods, and basketball team management systems. In this context, it is also necessary to appropriately increase the income of coaches, determine the competitive employment system, strictly implement the 
appointment system, change the previous administrative appointment model, make the coaching work specialized and responsible, and fully stimulate the enthusiasm of basketball coaches in the training and competition process.

\section{Improving the cultural quality of basketball players}

Basketball players should be arranged to learn cultural lessons appropriately on the basis of the content, rules, and characteristics of higher education. In addition to formulating relevant systems and contents for the life, learning, and training of the players, it is also necessary to make clear that basketball players belong to college student group. School should give play to the role of the system, establish a good communication and exchange model between college amateur basketball reserve talents and ordinary college students, provide them with sufficient and free basketball playing and training space, so that they can live and learn with other students together. In addition, school should also uphold the principle of "teaching students according to their aptitude", and choose the correct method to conduct scientific and effective management on the basketball players' life, learning, and training processes, so that they have a high level of cultural quality, laying a good foundation for the subsequent series of basketball training and competition works [8]

\section{Standardizing the cultivation of basketball reserve talents}

According to the content and requirements of the cultivation of basketball reserve talents, this work model can be optimized and reformed to ensure that the work has phased and systematic features. Against this background, school should pay attention to the innovation of college amateur basketball reserve talent cultivation model, make college basketball games presenting the characteristics of normalization, institutionalization, and massification, and achieve multiple talents cultivation methods and goals. In the cultivation of college amateur basketball reserve talents, school should also optimize the extra-curricular activities, training methods, coaching levels, and so on, and even maintain a good communication, cooperation, and interaction relationships with CBA coaches, delivering professional and high-quality talents for basketball teams, and achieving a good collaborative talents cultivation effect [9].

\section{Conclusion}

In summary, the collaborative innovation work in cultivation of amateur reserve basketball talents in colleges and universities is relatively complicated, and it is needed to concern and consider many specific tasks and contents. In college sports and basketball teaching, teacher should recognize the importance of this work, and comprehensively cultivate reserve talents based on the current situation of talent cultivation to improve the efficiency of college basketball related work. By changing the cultivation goal and reforming the competition system, the collaborative cultivation of amateur basketball reserve talents in colleges and universities can be innovated to make this work more standardized, provide talent reserves for professional basketball teams in China, and enable basketball players to have higher comprehensive competences and psychology level.

\section{References}

[1] Liu Wanwu. Thinking of Collaborative innovation based cultivation of amateur basketball reserve talents in colleges and universities [J]. Contemporary Sports Technology, 2016 (1): 35 36. (in Chinese)

[2] He Wei. Research on the current situation of cultivation of basketball reserve talents in colleges and universities and and the countermeasures [J]. Economic Research Guide, 2017 (10) 145-146. (in Chinese)

[3] Ou Yushuo. Research on the Problems of Basketball Reserve Talents Cultivation in Chinese Universities and the and Development Countermeasures [J]. Liaoning Sport Science and Technology, 2017, 39 (6): 112-114. (in Chinese)

[4] Zhang Di. Research on Basketball Reserve Talents Cultivation in Colleges and Universities $[\mathrm{J}]$. Contemporary Education Research and Teaching Practice, 2015 (7): 43-44. (in Chinese)

[5] Wang Enfei. Research on the Core Problems of Basketball Reserve Talents Cultivation in Colleges and Universities [J] Contemporary Sports Technology. 2018, 226 (04): 74 + 76. (in Chinese)

[6] Gong Shijun, Zou Yachun. Research on the Mode of Basketball Reserve Talents Cultivation in Chinese Universities [J]. Sport, 2018, 185 (09): 43-44. (in Chinese)

[7] Wang Cheng, Wang Jipeng. The Contents, Characteristics and Enlightenments of Training Mechanism for Reserving Basketball Talents in American Colleges and Universities [J]. The Guide of Science (Electronic Edition), 2016 (9): 115-115 (in Chinese)

[8] Xiong Zhenhua. New thinking of athletic basketball reserve talents cultivation in China $[\mathrm{J}]$. Contemporary Sports Technology, 2015, 5 (12): 210-210. (in Chinese)

[9] Sun Bo. New thinking of training athletic basketball reserve talents in China [J]. Contemporary Sports Technology, 2018, 8 (1): 248-248. (in Chinese) 